\title{
INTELIGÊNCIA COMO DISPOSITIVO DE PODER
}

\author{
LuÍSA SAAVEDra*
}

\begin{abstract}
RESUMO: O objetivo do presente estudo, é compreender a inscrição individual e social de discursos usados por alunas, em diferentes posiçôes de classe social, para explicar os seus sucessos académicos. Foram entrevistadas 19 alunas portuguesas do $11^{\circ}$ ano de escolaridade provenientes das classes trabalhadora e alta, com elevado rendimento académico. A Análise Foucaudiana do Discurso aponta para a importância da posição de classe na construçáo dos sujeitos relativamente à sua conceção de inteligência e ao sucesso escolar. A inteligência funciona assim como um dispositivo de poder que regula as relaçôes entre sujeitos de diferentes classes sociais.
\end{abstract}

Palavras-chave: Classe social; Discurso; Esforço; Inteligência.

\section{INTELLigenCE AS A POWER DEVICE}

ABSTRACT: The objective of the present study is to understand the individual and social inscription of discourses used by students from different social class positions to explain their academic achievement. Nineteen portuguese students, from the 11 th grade, with high academic performance and from the working class and upper class, in northern Portugal, were interviewed. Foucauldian Discourse Analysis points to the importance of class position in the construction of the subjects with respect to their concept of intelligence and academic success. Intelligence works as a power device that regulates the relations among subjects of different social classes.

Keywords: Social class; Discourse; Effort; Intelligence.

* Universidade do Minho, Escola de Psicologia, Braga, Portugal. E-mail de contato: luisasaavedra@sapo.pt. 


\section{L'INTELLIGENCE COMME DISPOSITIF DE POUVOIR}

RÉSUMÉ: L'objectif de cette étude est de comprendre l'inscription individuelle et sociale des discours utilisés par les apprenantes dans différentes positions de classe sociale, pour expliquer leurs succès académiques. Dix-neuf apprenantes portugaises de la 11 ème année de scolarité dotées d'un bon rendement scolaire issues des classes ouvrières et moyennes supérieures ont été interviewées. L'Analyse Foucaldienne du Discours souligne l'importance de la position de classe dans la construction des sujets concernant leur conception de l'intelligence et de la réussite scolaire. L'intelligence fonctionne aussi bien en tant que dispositif de pouvoir qui régit les relations entre les individus de différentes classes sociales.

Mots-clés: Classe sociale; Discours; Effort; Intelligence.

\section{Introdução}

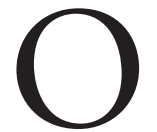

conceito de inteligência faz parte do senso comum, sendo usado na linguagem cotidiana para caracterizar pessoas ou trabalhos por elas realizados. Entrou no discurso da psicologia nos finais do século XIX e, desde então, tem dado azo a numerosos estudos e teorias que, ora se contestaram mutuamente, ora se aceitaram. Novos conceitos e abordagens foram introduzidos (e.g. inteligência emocional), sem que tenha havido preocupação em estudar a genealogia deste conceito ou os seus efeitos na identidade de cada indivíduo. A partir dos anos 70/80 do século passado, sob influência das perspetivas construcionistas sociais (GERGEN, 1999), do trabalho de Michel Foucault (e.g., [1971], 1997) e da Psicologia crítica (e.g., FOX, 2000; PARKER, 2007) começou, contudo, a criar-se uma tendência para investigar, questionar e desconstruir alguns conceitos básicos da psicologia.

Ao mesmo tempo estes movimentos conduzem a questionamento das metodologias empiricistas/positivistas sustentadas pela psicologia de mainstream. (GERGEN, 1999; PARKER, 2007) Apesar destas mudanças epistemológicas e metodológicas, o conceito de inteligência parece ter merecido pouca atenção por parte das perspetivas pós-modernas e críticas. Muito raras são as obras que se centraram na desconstrução ou questionamento deste conceito, sendo de destacar o trabalho de Anderson (1995) e, mais recentemente, o de Mike Rose (2004). Importa também salientar o trabalho realizado por Valerie Walkerdine (1998), neste âmbito, evidenciando o modo como os professores e professoras fazem atribuiçóes causais ao esforço ou à inteligência em função da classe social e género dos/das estudantes. 
Ao longo deste trabalho, procurarei evidenciar como este conceito pode ser conceptualizado como um dispositivo de poder (FOUCAULT, [1975] 2003) que tem servido para rotular, hierarquizar e subjugar. Esta hierarquização e subjugação ocorre, quer através da prática psicológica e do recurso a medidas de avaliação, quer pela forma como cada pessoa faz avaliaçóes sobre si e sobre os outros que, ora conferem valor e poder a uns, ora diminuem e oprimem outros. A inteligência segue, na verdade, o mesmo processo geral de desvalorização, discriminação e opressão de outros grupos minoritários sendo as mulheres, os negros e os pobres os grupos alvo de maior desvalorização nesta dimensão. (e.g., CHAMORRO-PREMUZIC; FURNHAM, 2006; GALTON, 1869/1999) Como a construção das nossas identidades se faz, em grande medida, a partir da imagem e do reconhecimento que os outros têm de nós (HABERMAS, 1983), estas imagens são altamente desfavoráveis na construção identitária dos grupos mais desfavorecidos. Importa por isso compreender como os conceitos científicos são apropriados pelos discursos do cotidiano e usado para localizar os sujeitos em determinadas posiçôes sociais.

Antes de avançar para o estudo que aqui me proponho apresentar, passarei primeiro em revista alguns marcos do conceito que evidenciam como o discurso científico se organiza em torno de contingências históricas e sociais, que Foucault designou de "vontade de verdade" (1997).

Francis Galton $(1865,1869 / 1999)$ foi o primeiro autor a tentar medir não só a inteligência como as diferenças intelectuais entre os grupos humanos. Influenciado por Charles Darwin, Malthuser e Spencer (ANDERSON, 1995), defendeu a inteligência como geneticamente dependente do quociente de inteligência dos progenitores e a possibilidade de distinguir as pessoas em função da família, "raça” e sexo. (GALTON, 1865; 1869/1999) Em "Hereditarygenius, itslaws and consequences", estabelece uma correlação positiva entre inteligência, êxito e hierarquia social (GALTON, 1869/1999) e sinalizando os indivíduos mais inteligentes, Galton propunha-se implementar um programa eugénico para aprimorar as características da raça humana eliminando, através da seleção artificial, os indivíduos inaptos. (ALMEIDA, 1983; ANDERSON, 1995) Tal como para outros autores, também para ele as mulheres seriam também portadoras de uma menor inteligência. (SANTOMÉ, 1995) A este propósito, é de salientar que nos primórdios da psicologia (finais do século XIX e princípios do século XX) a inferioridade intelectual da mulher encontrava-se alicerçada na inferioridade do seu cérebro, quer relativamente ao peso total, quer de diversas partes do mesmo. (WOOLEY, 1910) E como existia uma associação entre tamanho e fisiologia do cérebro e as capacidades cognitivas a inferioridade intelectual da mulher era assim confirmada. Por outro lado, a teoria da maior variabilidade do sexo masculino $^{1}$, confirmava a ideia de que as mulheres nunca poderiam chegar ao mesmo nível que os homens e que teriam que se contentar com a mediania. Além disso, 
acreditava-se que existiria uma incompatibilidade entre a energia gasta durante o período menstrual e aquela que seria necessária para a atividade intelectual. Numerosos estudos fazem alusão aos efeitos nefastos da escolaridade na redução do número de casamentos e de filhos das poucas mulheres que tinham estudado. Toda esta primeira fase de afirmação da psicologia como ciência é dominada pelo modelo médico, pela fisiologia e pelos estudos da perceção que são o garante da cientificidade. (SAAVEDRA; NOGUEIRA, 2006)

A partir dos anos 30/40 do século XX, e com os avanços da estatística, começam a procurar-se formas de avaliar a inteligência, tendo a análise fatorial tido um peso considerável nesta linha de investigação. A identificação das capacidades que explicavam as diferenças individuais, repartiam-se por três teorias distintas: as que defendiam a existência de um só fator comum a toda a atividade cognitiva (e.g., SPEARMAN, 1927); a existência de vários fatores independentes e ainda as que procuram conciliar estas duas perspetivas. (ALMEIDA, 1983; RIBEIRO, 1998) Apesar das divergências entre os autores nunca o próprio conceito foi questionado, nem a sua utilidade. Pelo contrário, em todas as perspetivas existe uma preocupação com o aperfeiçoamento psicométrico das medidas de avaliação, vulgarmente designadas por testes ou inventários. (RIBEIRO, 1998) A maior parte destas abordagens negligenciavam a dimensão desenvolvimental da inteligência postulando uma visão essencialista da mesma, como um traço inalterável, inscrito no indivíduo e que se manteria constante ao longo da vida.

A partir dos anos 1960 as abordagens à inteligência salientam a possibilidade de desenvolvimento cognitivo e o papel do contexto, destacando-se nomes como Sternberg (1985) e Gardner (1983). Num trabalho realizado em 1981, Sternberg, Conway, Ketron e Bernstein faziam referência a teorias implícitas que corresponderiam a crenças por parte das pessoas comuns acerca do que seria a inteligência e de como esta se manifestaria. Os resultados mostravam muitas semelhanças entre as conceçóes de leigos e certas teorias psicológicas da inteligência. Apesar de algum distanciamento das abordagens essencialistas, os métodos de avaliação e o apoio na análise fatorial continuam a pontuar estes trabalhos e a sua orientação positivista/empiricista.

Nos anos 1990 ocorrem novos desenvolvimentos, tendo sido então criado o conceito de inteligência emocional. (SALOVEY; MAYER, 1990) Novamente se avança na construção de instrumentos que permitam a sua avaliação tendo sempre por suporte a identificação de fatores e a validação de instrumentos. (MAYER; SALOVEY; CARUSO, 2002)

Mais recentemente e já neste século, surge um conjunto de preocupaçóes e estudos baseados no conceito de autoavaliação da inteligência. ${ }^{2}$ Estas investigaçóes continuam sem questionar o passado da psicologia na avaliação da inteligência. Apoiando-se sobretudo nas perspetivas cognitivas e emocionais da 
inteligência conduzem uma série de estudos que vêm, no entanto, ao encontro das preocupaçóes que fazem parte do estudo que aqui se apresenta, no que diz respeito ao papel do género e a classe social na perceção acerca da inteligência pessoal e da identidade. Estes estudos têm evidenciado que as mulheres subestimam a sua própria inteligência e que os homens a superestimam (CHAMORRO-PREMUZIC; FURNHAM, 2006; DAHL; LIFEWORK DESIGN GROUP, 2009; KUDRNA, FURNHAM; SWAMI, 2010; SWAMI; FURNHAM, 2010), o mesmo acontecendo com a classe social: os grupos mais favorecidos avaliam-se mais positivamente do que os menos favorecidos. (KUDRNA, FURNHAM; SWAMI, 2010) A inteligência poderá então ser concebida como um dispositivo de poder (FOUCAULT, 2003) que fica invisível e no interior do qual circulam novas intensidades de poder, refletindo as ideias mentais da época. Ao conceito de inteligência está também associado ao de norma tal como é definida pelo mesmo autor:

A norma designa sempre uma medida que serve para avaliar o que está conforme a regra e o que a distingue; não está mais ligada à ideia de retidão, esquadro, mas de "mediana" - a norma torna-se agora o parâmetro para opor normal/anormal, normal/ patológico. (WELLAUSEN, 2007, p.16)

Efetivamente, quando se fala em inteligência recorre-se ao conceito estatístico de "média". A inteligência individual pode então ser classificada como média, acima e abaixo da média.

Questionado, assim, estas procuras positivistas de verdade e tendo como suporte teórico o construcionismo social e a psicologia crítica, o objetivo subjacente ao estudo que seguidamente se apresenta é contribuir, ainda que de forma modesta, para pequenas transformaçóes da sociedade e da psicologia (FOX; PRILLELTENSKY; AUSTIN, 2009; PARKER, 2007), questionando um dos seus pilares básicos (a inteligência) e pondo em evidência como este conceito é, geralmente, usado para perpetuar desigualdades entre aqueles e aquelas que se encontram no topo e na base da pirâmide social. Implicitamente são questionados os valores, pressupostos e práticas da psicologia dominante, recorrendo a uma metodologia qualitativa. Deste modo será possível compreender e avaliar a repercussão dos discursos construídos pela psicologia e o impacto político e ético destas teorias. (FOX; PRILLELTENSKY; AUSTIN, 2009)

\section{Suporte metodológico}

Do ponto de vista metodológico, o ponto de partida para este trabalho foi a Análise Foucaudiana do Discurso (WILLIG, 2008), que agrega um conjunto 
de abordagens que valorizam as relaçóes entre a linguagem e o poder e a função do discurso como forma de crítica social e cultural. Sendo um "ramo" dentro da análise do discurso, partilha com esta perspectiva uma série de assumpçóes de entre as quais se destaca uma maneira particular de encarar a linguagem: náo como uma entidade abstracta meramente composta por regras gramaticais, mas como um meio para analisar interacçôes sociais. (POTTER, 1997) De uma forma geral, a análise do discurso representa um meio de ultrapassar as abordagens cognitivas do comportamento e centrar-se na natureza socialmente construída da realidade. (GILLES, 1999)

A Análise Foucaudiana do Discurso permite pôr em causa construçôes e conceitos dominantes da psicologia tais como a doença mental, a inteligência, a personalidade, entre outros, mostrando, através da sua desconstruçáo, como eles poderiam ser diferentes; como as categorias que usamos para descrever a realidade cumprem determinadas funçóes sociais e de poder. (PARKER, 1992) Através da desconstrução e crítica destes discursos é possível identificar posiçôes alternativas e promover estratégias de resistência. (WILLIG, 1999) Por exemplo, referir-se a si próprio como membro de determinados grupos sociais pode salientar aspectos mais escondidos da identidade social e permitir a eclosão de novas formas de se relacionar com os outros. O discurso pode provocar mudanças no sentido de que, como refere Foucault (1994, p. 104), "O discurso veicula e produz poder; reforça-o, mas também o mina, o expóe, o torna frágil e permite impedi-lo de avançar”.

O estudo foi realizado através de entrevistas semiestruturadas a 19 alunas portuguesas do Ensino Público ${ }^{3}$, a frequentar o $11^{\circ}$ ano de escolaridade e provenientes tanto de classes sociais elevadas, como da classe trabalhadora, que apresentassem elevado rendimento escolar (classificaçóes entre 17 e 20, numa escala de 0 a 20). As alunas foram selecionadas em função destes dois critérios acumulados: ter sucesso académico e pertencer a classes sociais bem marcadas. As entrevistas foram todas realizadas na escola em que as alunas frequentavam e áudio-gravadas. As questôes tinham como objetivo compreender como as participantes explicavam o seu sucesso escolar e quais as razóes (atribuições causais) que invocavam para o mesmo.

Após a transcrição integral do material gravado e uma leitura detalhada e profunda do material de análise, foram identificados diferentes formas de construir o sucesso académico. Estas formas de "falar" foram chamadas de construçôes discursivas seguindo as indicaçóes de Carla Willig (2008). Os excertos apresentados para ilustrar cada uma dessas construçóes discursivas sáo frases integrais ou fragmentos de frases selecionadas a partir do todo o material produzido. Posteriormente estas foram integradas em discursos mais amplos, que por sua vez foram alvo de análise relativamente à sua função ou às práticas a que conduzem bem como à forma como condicionam diferentes posiçôes subjetivas, experiências e sentimentos particulares. Estas designaçóes não devem, contudo, 
ser entendidas como passos rígidos e sequenciais. Devem, sim, ser entendidos como guias de referência e orientação. Por essa razão, não serão apresentados de uma forma sequencial, mas antes procurando o entrelaçamento das últimas quatro fases da análise.

\section{Construindo o sucesso académico}

A leitura profunda das transcriçóes das entrevistas permitiu identificar três construçóes discursivas, ou seja, diferentes formas de construir o mesmo objeto discursivo que neste caso é o sucesso académico. Foram assim identificadas três formas distintas de construir este objeto discursivo: o "discurso da igualdade", o "discurso da diferença" e o "discurso da marginalidade".

O discurso da igualdade é proferido, essencialmente, por alunas da classe média/alta (pais e mães licenciados/as que são engenheiros/as, advogados/as, professores/as) e por uma aluna que pertenceria, dentro da designação de Giddens (1975), à "nova classe média”. ${ }^{4}$

A frase paradigmática deste discurso é de que "toda a gente é inteligente", valorizando-se outros determinantes dos resultados escolares, tal como a atenção nas aulas, a concentração ("eu acho que toda a gente é inteligente, basta é puxar um bocadinho pela cabeça, concentrar-se, ter atenção ao que faz, pronto...”SS-H) e o estudo ("Eu geralmente estudo tudo e aprofundadamente, não acho que tenha nenhuma capacidade, se calhar estou mais atenta que os outros nas aulas - AI-C; "também estudo, não é?, faço os meus resumos e assim... o que me ajuda imenso para os testes, e estou atenta nas aulas sobretudo, apanho imenso nas aulas" - B-G).

O reverso da medalha consiste, consequentemente, na responsabilização dos seus colegas que têm insucesso escolar e que são negativamente considerados "malandros":

Acho que todos os meus colegas eram capazes de tirar boas notas se estivessem mais concentrados nas aulas, estudassem quando chegassem a casa e assim, mas pronto, são todos malandros... quase todos...(SS-H).

Ainda no "discurso da igualdade", existe o recurso a uma visão hereditária da inteligência para explicar como, sendo todos as pessoas igualmente inteligentes, umas pessoas obtêm melhores resultados do que outras:

Bem, isso claro que depende da própria pessoa e também se são capacidades já biológicas, porque há pessoas que não são capa- 
zes de realizar certas tarefas, por exemplo na área de educação física... há pessoas que não são capazes de realizar certas tarefas que outras são; na área intelectual é exactamente a mesma coisa (JG-H).

Por contraponto no "discurso da desigualdade" é assumida uma diversidade de inteligência entre os alunos e alunas e é unicamente utilizado por alunas da classe trabalhadora. Esta diversidade traduz-se em classificaçóes escolares diferenciadas. Quem tem menos inteligência tem de compensar esta falha através de um profundo envolvimento na atividade académica:

Acho que as minhas notas são o fruto do meu trabalho, acho que trabalho para ter as notas que tenho... às vezes não são tão boas como eu queria que fossem, mas... mas são o fruto do meu trabalho...(CS-H).

Eu estudo. Sei que há muita gente que tem melhor notas do que eu, que não estuda tanto como eu, mas pronto, eu tenho que estudar... (MM-H).

Esta última formulação deixa assim antever a perspectiva de que existem pessoas mais inteligentes, que precisam estudar menos e que, apesar disso, obtêm um rendimento escolar mais elevado, ideia reforçada mais adiante quando a mesma participante refere:

Tenho pessoas na minha turma que se vê que são inteligentes, nas aulas são capazes de resolver um problema que mais ninguém consegue e eles resolvem bem, na hora. Eu há coisas que náo consigo na hora, ainda tenho que estar ali a pensar e eles facilmente dizem alguma coisa... eu, eu não... (MM-H).

O "discurso da marginalidade" é utilizado unicamente por uma aluna da classe trabalhadora (mãe cozinheira; pai mecânico de automóveis) que apresenta elevado rendimento escolar e que ao longo de toda a entrevista assume um posicionamento crítico face à escola, aos professores e à sua feminilidade, assumindo a sua inteligência a par com o seu pouco envolvimento no estudo. Ao contrário do "discurso da igualdade", no qual os colegas que não estudam são criticados, neste discurso nota-se um certo mal-estar perante os colegas que estudam mais e tiram pior notas.

Eu muitas vezes sinto-me mal e isso é muitas vezes mesmo, porque eu vejo colegas meus que se esforçam muito mais que eu e não conseguem tirar as notas que eu tiro, porque eu se há uma coisa que nunca soube foi estudar $(\mathrm{O}-\mathrm{H})$. 
É uma aluna que se assume simultaneamente como inteligente ("se calhar associo muito rapidamente as coisas e memorizo e depois encontro sempre uma lógica, capacidade de encadeamento, e depois muita memória fotográfica que é uma coisa que eu tenho") e como "pouco estudiosa”, embora, contrariando afirmaçōes anteriores, assuma que faz exercícios para as disciplinas de matemática e físico-química. Esta aluna usa, de uma forma geral, um discurso crítico que perpassa por diversas dimensóes da sua vida: prefere amigos do sexo masculino, pensa seguir engenharia mecânica, não quer casar, nem ter filhos.

\section{Apropriação dos discursos da psicologia sobre sucesso académico}

As construçôes discursivas a que estas alunas recorrem são apropriaçóes de discursos que circulam no espaço social e científico acerca da inteligência e do esforço, encarados frequentemente como antagónicos, para explicar o sucesso académico.

Como se viu anteriormente, na psicologia houve um percurso baseado numa conceção hereditária da inteligência para, a partir dos anos 1970, que passaram a conceptualizar a inteligência como fruto da interacção e relação com o meio ambiente. (GARDNER 1983, 1999; STERNBERG, 1985, 1996) Neste sentido poder-se-ia dizer que as capacidades intelectuais não são uma propriedade dos indivíduos. (ANDERSON, 1995) Outros fatores, para além da inteligência, entraram também no discurso da psicologia para explicar as razóes do sucesso de uns e do fracasso de outros; entre eles contam-se a motivação, a concentração na tarefa, o esforço desenvolvido para a realização da tarefa, as experiências anteriores, o treino e a autorregulação de aprendizagem (ROSÁRIO, 2003), que integra muitas das dimensóes anteriormente referidos.

Ao longo das várias entrevistas, e nos excertos apresentados, pode-se observar que alguns destes discursos, ou partes deles, foram apropriados e recombinados dando-lhes uma nova configuração. Tanto o "discurso da igualdade", como o "discurso da desigualdade" são, no seu conteúdo explícito, dominados pela ideia do esforço no estudo, da concentração, em simultâneo com uma concepção hereditária ou biológica das aptidóes intelectuais. Do ponto de vista das teorias psicológicas estas duas perspetivas são incompatíveis, demonstrando assim contradiçóes no discurso e na sua apropriação, tanto mais que em nenhuma das produçóes discursivas aparece a ideia de que a inteligência é influenciada pela cultura ou que se desenvolve com o treino (náo é dito que o esforço influencie o treino). A inteligência aparece, assim, como um traço psicológico ou biológico estável. Algo que se tem em maior ou menor quantidade e com o qual se nasce ou surge em nós de uma forma que não é clarificada. Quando não se tem inteligência 
suficiente esta pode ser compensada pelo estudo, pela atenção e pela concentração, como é muito claramente evidenciado pelas alunas das classes mais baixas. No entanto, a situaçáo é de desvantagem, quer pelo tempo gasto em estudo, quer pela menor rapidez em responder aos desafios colocados pelas atividades escolares: "Eu há coisas que não consigo na hora, ainda tenho que estar ali a pensar e eles facilmente dizem alguma coisa... eu, eu não...” (MM-H).

Por outro lado, o discurso de culpabilização dos colegas que têm menos capacidade e piores notas ("são uns malandros") entra em contradição com uma conceção hereditária que os deveria desresponsabilizar. Talvez subjacente a esta afirmação esteja a ideia de que eles poderiam estudar mais para compensar a tal falta hereditária, mas tal não é efetivamente explicitado. Estas duas abordagens demonstram, assim, um conflito entre uma conceção em que a inteligência se mantém inalterada ao longo do tempo, de que é algo com que nascemos e não se pode modificar, e a motivação que é um conceito menos ameaçador do que inteligência para a autoestima individual, mas que ao mesmo tempo implica agência individual. Mas também o discurso da "marginalidade", não foge a uma conceção tradicional da inteligência e do sucesso académico. É, contudo, o único onde o recurso a uma inteligência superior é utilizado sem subterfúgios para explicar o rendimento académico.

\section{Construindo práticas e subjetividades}

Qual a vantagem/desvantagem ou função de que se construir o objeto discursivo acentuando que "somos todos igualmente inteligentes" e de apoiar a explicação das diferenças de realização académica na motivação, no esforço e, ao mesmo tempo, em fatores biológicos? Nas conceçôes destas alunas a motivação e o esforço levam a uma responsabilização dos alunos que têm insucesso a si próprios, não questionando porque é que esses colegas não são agentes da sua actividade escolar ou deixando essa explicação para causas individuais e, eventualmente, de personalidade como se pode inferir da afirmação da aluna SS-H "são malandros". Esta conceção individualista e de culpabilização da vítima submerge outras visões mais sociais e culturais do insucesso, nomeadamente, como o currículo oculto e formal se estrutura, veiculando e reproduzindo uma ideologia e cultura dominantes.

O "discurso da diferença” salienta, de uma forma inequívoca, a supremacia dos dotados intelectualmente sobre os menos dotados. Tal como há cerca de 200 anos parece haver uma associação entre a inteligência, a classe social e o rendimento económico, possuindo as pessoas de classes mais baixas e menor rendimento académico, uma menor inteligência. (ANDERSON, 1995) As alunas recorrem a uma visão dominante e hegemónica da sociedade sobre o modo como a 
inteligência está distribuída e é atribuída, abarcando para si próprias a menor parte dessa mesma distribuição. Este menor "dote" cognitivo tem que ser compensado com o esforço, única atribuição causal controlável. $\mathrm{O}$ modo como acentuam de uma forma inegável a importância do seu esforço e a diferença entre elas e outros alunos e alunas, que foram cognitivamente mais beneficiados, evidencia como se encontram submetidas a esse discurso dominante.

No "discurso da marginalidade" está subjacente a mesma ideologia assente nas bases biológicas, pois a aluna que recorre a este discurso reconhece-se como privilegiada por ser inteligente e duma forma algo especial: "Porque a minha médica diz que eu sou uma sobredotada, mas eu acho que não [...]” (O-H). No entanto, nesta aluna há uma espécie de luta, uma contestação e resistência a este discurso dominante sobre a inteligência e aos conceitos relacionados para explicar o alto rendimento académico. Sendo de uma classe que não é geralmente beneficiada com este atributo pessoal assume uma posição de resistência que não é, no entanto, isenta de conflitos consigo própria e os outros "[...] porque eu muitas vezes sinto-me mal e isso é muitas vezes mesmo, porque eu vejo colegas meus que se esforçam muito mais que eu e não conseguem tirar as notas que eu tiro [...]".

Em última análise poder-se-ia considerar que a principal função dos dois discursos - o de dominação e o de submissão - é encobrir a existência de relaçóes de poder e hierarquia entre os alunos e alunas, que apesar de apresentarem o mesmo nível de sucesso académico são provenientes de classes sociais diferentemente valorizadas na sociedade. O sucesso, por si só, não coloca na mesma posição subjetiva todos os alunos e alunas, distinguindo aqueles que têm sucesso através da inteligência (mesmo que tal não seja abertamente declarado) de aqueles e aquelas que o obtêm à custa do esforço, sendo que no primeiro caso se encontram as participantes provenientes de uma classe social mais favorecida e no segundo as menos favorecidas.

Tanto o "discurso da igualdade" como o "discurso da diferença” apresentam uma versão da realidade como um espaço onde se produzem e reproduzem as desigualdades sociais. Parecem, no entanto, existir diferenças nas posiçóes subjetivas que o discurso permite. No "discurso da diferença", adivinha-se uma maior consciência da posição de submissão. No "discurso da igualdade" não existe consciência da dominação, como se o poder se tornasse invisível para aqueles que o detêm. (KITZINGER; WILKINSON, 1996) Daí que não queiram assumir a diferença e defendam que "somos todos igualmente inteligentes". Esta invisibilidade do poder nos grupos dominantes está patente no discurso da aluna JG-H:

\section{L.S. - Não te consideras então mais do que os outros?}

JG-H - Não... nunca considerei, muitas vezes consideram-me e às vezes até não me sinto assim muito... 


\section{L.S.- Consideram-te...}

JG-H - Sim, como se fosse superior aos outros, mas eu sinto-me mal com essa situação, não sei lidar muito bem, porque acho que também tem a ver com a minha educação, eu fui educada naquele sentido de que todas as pessoas são iguais e acredito sinceramente nisso (...).

Esta incapacidade das alunas mais favorecidas em perceber a posição de poder e de capacidade intelectual, e das alunas mais desfavorecidas em perceber a visibilidade da subordinação tem consequências distintas ao nível das práticas e das subjetividades. O "discurso da igualdade" permite aceder a uma consciência positiva de si, a uma segurança pessoal sem grandes conflitos consigo próprias e com os outros significativos, no sentido em que as alunas caminham na mesma direcção social e cultural dos progenitores. Neste ponto parece conveniente salientar, contudo, o caso da aluna SS-H que sendo proveniente da "nova classe média", é talvez de todas as alunas que se constroem através deste discurso aquela que revela maiores contradiçóes e ambiguidades ${ }^{5}$ e que mais violentamente se refere os/as colegas que fracassam academicamente, como já acima foi referido. Esta aluna, em termos de pertença de classe e pelos recursos discursivos utilizados, parece estar numa posição particularmente difícil no que diz respeito à sua subjetividade. Teria à sua escolha um ou outro dos discursos ou poderia ter construído um discurso alternativo, mas decidiu-se por aquele que, eventualmente, se afigura como mais protector para a sua imagem e que mais facilmente lhe permite aceder a uma mobilidade social menos conflituosa consigo própria.

Mas a invisibilidade do poder tem ainda outra consequência para a subjetividade das alunas que recorrem ao discurso dominante: permitir-lhes estabelecer relaçóes não conflituosas com as colegas que são alvo desse mesmo poder, pois este encontra-se mascarado num discurso de igualdade: "eu fui educada naquele sentido de que todas as pessoas são iguais e acredito sinceramente nisso" (JG-H).

Em contrapartida, a ideia de um défice na inteligência tem consequências negativas para a identidade das alunas da classe trabalhadora, mesmo para a que assume um "discurso de marginalidade". Sobretudo para aquelas que adotam o "discurso da diferença", não é nada emancipador considerarem que só conseguem obter sucesso através de um trabalho escolar intenso, mas não só escolar. Como salienta Diane Reay (1997), as alunas da classe trabalhadora têm que aprender uma linguagem diferente daquela que aprenderam no ambiente familiar, silenciando a linguagem da infância, a par de toda uma expressão e posturas não verbais que distinguem a classe trabalhadora da classe média, que se relacionam com um determinado sentido de feminilidade e da sexualidade feminina. A par destas dificuldades outras surgem ligadas com o sentido de individualismo e meritocracia. Estas alunas, tirando partido de um sistema social de desigualdade, são 
as provas vivas de que o rendimento académico depende das aptidóes pessoais e não da classe a que se pertence, ou seja, de um sistema que sendo desigual recorre a sofisticados mecanismos para ocultar essa desigualdade. Invocando Chisholm (1995, citada por REAY, 1997, p.21), dir-se-ia que: "sentir que se pode tomar o seu destino nas suas próprias mãos pode ser pessoalmente emancipador, mas não é necessariamente socialmente emancipador.".

Portanto, para as alunas da classe trabalhadora o elevado rendimento escolar significa a recusa de todo o sistema de significado de classe e, ao mesmo tempo, é uma prova de meritocracia que serve para desvalorizar aqueles que fracassam, contribuindo para um sentimento de deslealdade para com o seu grupo de pertença. Mas, paralelamente, coloca-as numa posição complexa face às colegas do grupo dominante. São essas colegas que lhes dão a dimensão da sua própria posição de subordinação, pois é na relação com elas que esta subordinação é construída. Não serem reconhecidas como iguais, mesmo estando no mesmo patamar de sucesso académico, dificulta o seu posicionamento no quadro social. E, não posso deixar de concordar inteiramente com Taylor (1994, p. 58), quando afirma que "[...] a projeção sobre o outro de uma imagem inferior ou humilhante pode deformar e oprimir até o ponto em que essa imagem seja internalizada [...]". Assim, estas alunas parecem estar no meio de dois fogos: nem estão inteiramente com o seu grupo de pertença, nem podem estar inteiramente com os/as outros/as.

Se analisarmos, par a par, o "discurso da diferença” e o "discurso da marginalidade" parece ser possível inferir que no último discurso há ainda uma maior consciência do exercício do poder pela classe dominante do que no "discurso da diferença” e que se traduz num sentimento de culpa face aos colegas: "porque eu muito vezes sinto-me mal e isso é muitas vezes mesmo, porque eu vejo colegas meus que se esforçam muito mais que eu e não conseguem tirar as notas que eu tiro" (aluna $\mathrm{O}-\mathrm{H}$ ). Este sentimento de culpa e vergonha é mais acentuado pelo facto de reconhecer que é inteligente e que não precisa de estudar não podendo, por isso, esconder-se atrás de um intenso trabalho escolar. Esta é, por isso, a aluna que mais consciente está dos custos que tem para si própria o assumir destas posiçóes e do lugar de excepção que ocupa face às suas colegas. Para ela o conflito com os outros parece ainda estender-se aos professores e à escola em geral. É, talvez a consciência da sua posição que favorece, precisamente, os seus discursos de resistência que não chegam a ser emancipatórios pelo menos no que se refere ao conceito de inteligência e à sua relação com o rendimento académico. Em qualquer dos casos estes dois discursos constroem sujeitos subjugados e marginalizados na escola face a um grupo que é visto como dominante e privilegiado. Em contrapartida, o grupo dominante, frente a vergonha e a culpa de se saberem privilegiados ocultam, perante si próprios, este processo perante uma capa de igualdade defendendo que "somos todos igualmente inteligentes". 


\section{Conclusão}

As várias produçóes discursivas apresentadas ao longo deste texto evidenciam a íntima associação entre inteligência, sucesso académico e poder. A inteligência pode, então, ser lida como um dispositivo de poder, no sentido em que o termo poder é usado por Michel Foucault ([1976], 1994), ou seja, como algo que está em toda a parte, que se produz nas relaçóes sociais, que não é fixo ou associado a um Estado ou grupo específico. Apoiando-se em determinadas conceçóes de saber, derivadas de teorias "cientificamente" formuladas, as participantes deste estudo "escolhem" discursos que produzem sujeitos que cumprem normas construídas em função das desigualdades entre os grupos. As poucas alunas da classe trabalhadora que fogem à norma ficam na desconfortável posição de traírem o seu grupo de pertença e fazerem face a um grupo dominante. Assumem, por isso, um discurso de submissão e subjugação e evitam discursos de resistência ou emancipação. Por outro lado, as alunas da classe mais favorecida, negam a existência de uma regra/norma protegendo-se, desta forma, da responsabilidade que lhes poderia ser atribuída. Se a dispositivo implica uma estratégia poderíamos então questionar: para que serve este dispositivo? Acima de tudo parece ter por efeito, manter a escola como um local isento de conflitos, de "lutas de classe". Os discursos psicológicos da inteligência, motivação e do esforço parecem fornecer uma série de sofisticadas estratégias que permitem que cada sujeito se construa mantendo o seu lugar sem questionar as políticas educativas subjacentes e sem questionar as diferenças de poder que os diversos grupos possuem na escola.

O conceito de inteligência (e outros que parecem compensar a sua falha, tais como motivação e esforço) parece assim ter por função regular as relaçóes de poder entre as alunas das diferentes classes sociais. Mas, para além dos efeitos individuais destes discursos, ressalta também a forma como os discursos científicos servem de alicerce aos discursos que circulam socialmente. Importa, por isso, que as abordagens à inteligência invistam os seus esforços no desenvolvimento de perspetivas teóricas inspiradas em visóes epistemológicas construcionistas e críticas, abandonando posições essencialistas, que reforçam uma conceção estática e inalterável da inteligência. Esta mudança epistemológica poderá contribuir para iguais alteraçóes metodológicas em que a psicometria e construção de instrumentos dê lugar à auscultação das pessoas e grupos ou outras formas de inquérito. Só com esta mudança será possível desconstruir a visão essencialista e determinista da inteligência e a forma como esta se encontra disseminada na sociedade e nos discursos do cotidiano, permitindo a construção de discursos alternativos e a possibilidade da sua apropriação social. Tendo em conta a forma naturalizada como o conceito de inteligência é utilizado parece difícil que este movimento parta de movimentos ou resistências sociais e compete, por isso, aos investigadores e aos profissionais, se assim o quiserem, a responsabilidade desta mudança. 


\section{Notas}

1. Esta perspetiva significa que a inteligência ocupa posiçôes extremas, desde os grandes génios aos grandes débeis intelectuais.

2. Outros autores referiram-se a este conceito através de outras designaçóes tal como self-estimates of intelligence (FURNHAM, 2001), intelligence c (EYSENCK; EYSENCK, 1985).

3. Ao contrário do Brasil, em Portugal o Ensino Publico continua a ser garante de grande qualidade de ensino e é frequentado por estudantes de todas as origens sociais. Isto não significa que todas as Escolas Públicas sejam de grande qualidade, mas sobretudo nas grandes cidades, isto é possível devido ao facto de existirem professores com grande experiência e muitos anos de carreira que acabam sendo mais bem remunerados que os que se encontram no Ensino Privado. O Ensino Privado é unicamente frequentado por aqueles e aquelas que podem pagar elevados custos, sendo muitas vezes o recurso de alunos/as com mais dificuldades académicas ou para obtençáo de elevadas classificaçóes escolares para os cursos superiores que exigem médias de acesso acima dos 18 valores, numa escala de 0 a 20.

4. A "nova classe média" integra, nos países anglo-saxónicos, os trabalhadores não manuais sem propriedades e os designados "colarinhos-brancos". Os pais desta aluna têm o $12^{\circ}$ ano de escolaridade, sendo a mãe funcionária dos correios e o pai empregado bancário e, neste sentido, poderia ser considerada não da classe trabalhadora, mas da "nova classe média". (GIDDENS, 1975)

5. Alguns destes excertos são exemplo dessas contradiçôes "[...] acho que todos os meus colegas eram capazes de tirar boas notas se estivessem mais concentrados nas aulas, estudassem quando chegassem a casa [...]"; "Não, só estudo nas vésperas dos testes, não sou daquelas que chega a casa e fazem... desde o $7^{\circ}$ ano que já não faço TPC, sou daquelas que só estudam nas vésperas dos testes [...]"; "nunca gostei de ficar à frente, sempre atrás, por isso é que eu estou mais distraída, [...] eu estou sempre a conversar ou a fazer desenhinhos com ela [...] mas atenta não estou”.

\section{Referências}

ALMEIDA, L. S. Teorias da inteligência. Porto: Ediçóes Jornal de Psicologia, 1983.

ANDERSON, M. L. The many and varied social constructions of intelligence. In: SARBIN, T. R.; KITSUSE, J. I. (Org.). Constructing the social. London: Sage, 1995. p. 119-138.

CHAMORRO-PREMUZIC, T.; FURNHAM, A. Personality and self-assessed intelligence: Can gender and personality distort self-assessed intelligence? Educational Research and Reviews, Maryland Heights, v.1, n. 7, p. 227-233, 2006.

DAHL, D.; LIFEWORK DESIGN GROUP. Self-assessed intelligence in adults: The role of gender, cognitive intelligence and emotional intelligence. Canadian Journal of Career Development, Newfoundland and Labrador, v. 8, n. 1, p.32-38, 2009.

EYSENCK, H. J.; EYSENCK, M. W. Personality and Individual Differences: a natural science approach. New York: Plenum Press, 1985. 
FOUCAULT, M. História da sexualidade I - A vontade de saber. Lisboa: Relógio D' Água, 1994. (Originalmente publicado em 1976).

. A ordem do discurso - aula inaugural no Collège de France, pronunciada em 2 de Dezembro de 1970. Lisboa: Relógio D’ Água, 1997. (Originalmente publicado em 1971).

. Vigiar e punir: história da violência nas prisões. (Raquel Ramalhete, trad.). Petrópolis: Editora Vozes, 2003. (Obra original publicada em 1975).

FOX, D.; PRILLELTENSKY, I.; AUSTIN, S. Critical psychology: an introduction. 2. ed. London: Sage, 2009.

FURNHAM, A. Self-estimates of intelligence: Culture and gender difference in self and other estimates of both general $(\mathrm{g})$ and multiple intelligences. Personality and Individual Differences, Kidlington, v. 31, p. 1381-1405, 2001.

GALTON, F. Hereditary talent and character, 1865. Disponível em: <http://psychclassics. yorku.ca/Galton/talent.htm>. Acesso em: 10 jan. 2011.

. Hereditary Genius: An Inquiry into Its Laws and Consequences. London: Macmillan, 1869 (Reprinted, Bristol: Thoemmes Press, 1999.

GARDNER, H. Frames of Mind: The theory of multiple intelligences. New York: Basic Books, 1983.

GERGEN, K. J. An invitation to social construction. London: Sage, 1999.

GIDDENS, A. A estrutura de classes nas sociedades avançadas. Rio de Janeiro: Zahar Editores, 1975.

GILLES, V. An analysis of the discursive positions of women smokers: implications for practical interventions. In: WILLIG, C. (Org.). Applied discourse analysis: social and psychological interventions. Buckingham: Open University Press, 1999. p. 66-86.

HABERMAS, J. Para a reconstrução do materialismo histórico. São Paulo: Brasiliense, 1983.

KITZINGER, C.; WILKINSON, S. Deconstructing heterosexuality: a feminist social-constructionist analysis. In: CHARLES, N.; HUGHES-FREELAND, F. (Org.). Practising Feminism: Identity, Difference, Power. London: Routledge. 1996. p. 135-155.

KUDRNA, L.; FURNHAM, A.; SWAMI, V. The influence of social class salience on self-assessed intelligence. Social Behavior and Personality, Palmerston North, v. 38, n. 6, p.859-864, 2010.

MAYER, J.; SALOVEY, P.; CARUSO, D. Mayer-Salovey-Caruso Emotional Intelligence Test (MSCEIT): user's manual. Toronto: Multi-Health Systems, 2002.

PARKER, I. Revolution in Psychology: alienation to Emancipation. London: Pluto Press, 2007.

. Discourse dynamics: critical analysis for social and individual psychology. London:

Routledge, 1992. 
POTTER, J. Discourse analysis as a way of analysing naturally occurring talk. In: SILVERMAN, D. (Org.). Qualitative Research. London: Sage, 1997. p. 144-160.

REAY, D. The Double Bind of Working Class Feminist Academic: The success of Failure or the Failure of Success? In: MAHONEY, P; ZMROCZEK, C. (Orgs.). Class Matters: Working Class Women's Perspectives on Social Class. London: Taylor and Francis, 1997. p. 18-29.

RIBEIRO, I. Mudanças no desempenho e na estrutura das aptidôes. Braga: Centro de Educação e Psicologia, 1998.

ROSÁRIO, P. S. (Des)ventures do Testas: estórias que ensinam a pensar e a estudar. Porto: Porto Editora, 2003.

ROSE, M. The Mind at Work: Valuing the Intelligence of the American Worker. London: Penguin Books, 2004.

SAAVEDRA, L.; NOGUEIRA, C. Memórias sobre o feminismo na psicologia: para a construção de memórias futuras. Memorandum, Belo Horizonte, v. 11, p. 113-127, 2006.

SALOVEY, P.; MAYER, J. D. Emotional intelligence. Imagination, Cognition, and Personality, Amityville, v. 9, n. 3, p. 185-211, 1990.

SANTOMÉ, J. T. O curriculum oculto. Porto: Porto Editora, 1995.

SPEARMAN, C. The abilities of man. New York: Macmillan, 1927.

STERNBERG, R. J. Beyond IQ: a triarchic theory of human intelligence. New York: Cambridge University Press, 1985.

. et al. People's conceptions of intelligence. Journal of Personality and Social Psychology, Washington DC, v. 41, p. 37-55, 1981.

SWAMI, V.; FURNHAM, A. Self-assessed intelligence: Inter-ethnic, rural-urban, and sex differences in Malaysia. Learning and Individual Differences, Maryland Heights, v. 20, n. 1, p. 51-55, 2010.

TAYLOR, C. El multiculturalismo y la política del reconocimiento. México: Fondo de Cultura Económica, 1994.

WALKERDINE, V. Counting girls out: girls and mathematics. London: Falmer Press, 1998.

WELLAUSEN, S. S. Os dispositivos de poder e o corpo em Vigiar e Punir, 2007. Disponível em: <http://www.unicamp.br/ aulas/pdf3/26.pdf>. Acesso em:12 set. 2012.

WILLIG, C. Introduction: making a difference. In: WILLIG, C. (Org.). Applied discourse analysis: social and psychological interventions. Buckingham: Open University Press, 1999. p. 1-21.

Foucauldian Discourse Analysis, In: WILLIG, C. (Org.). Introducing Qualitative Research in Psychology. London: Open University Press, 2008. p. 112-131. 
Inteligência como dispositivo de poder

WOOLLEY, H. T. A review of the recent literature on the psychology of sex. 1910. Disponivel em: <http://psychclassics.yorku.ca/Thompson/psychsex.htm>. Acesso em:10 jun. 2011.

Recebido em 13 de fevereiro de 2013.

Aprovado em 14 de fevereiro de 2014.

DOI: http://dx.doi.org/10.1590/ES0101-73302015111423 